\title{
Psychiatric Morbidity among Adolescents Girls Incarcerated at Kirigiti and Dagoretti Rehabilitation Schools in Kenya
}

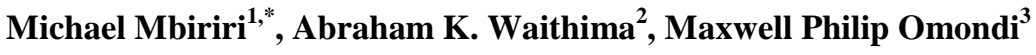 \\ ${ }^{1}$ School of Humanities and Social Sciences, Daystar University, Nairobi, Kenya \\ ${ }^{2}$ Development Institute, Economics and Director, Daystar University, Nairobi, Kenya \\ ${ }^{3}$ School of Nursing, Mount Kenya University, Nairobi, Kenya \\ *Corresponding author: mikembiriri@gmail.com
}

\begin{abstract}
Studies on juvenile delinquents have shown an overlap between delinquency and psychiatric disorder such as depression, post-traumatic stress disorders (PTSD, conduct disorders (CD) and attention deficit hyperactivity disorder (ADHD). This study investigated the prevalence of psychiatric morbidity among adolescent girls in selected rehabilitation schools in Kenya. The study sample had a total of 78 purposely selected adolescents in the two rehabilitation schools. The research found that the overall prevalence of depression was $66.7 \%$ that of anxiety disorder was $70.5 \%$, while the prevalence of conduct disorder was $55.1 \%$.In addition. This article has shown high presence of psychiatric morbidity among adolescent girls, incarcerated at Kirigiti and Dagoretti rehabilitation schools. These juvenile needs mental treatment as a key rehabilitation measure.
\end{abstract}

Keywords: depressive, anxiety, conduct disorder, adolescents, psychiatric morbidity

Cite This Article: Michael Mbiriri, Abraham K. Waithima, and Maxwell Philip Omondi, "Psychiatric Morbidity among Adolescents Girls Incarcerated at Kirigiti and Dagoretti Rehabilitation Schools in Kenya." American Journal of Applied Psychology, vol. 5, no. 2 (2017): 57-62. doi: 10.12691/ajap-5-2-4.

\section{Introduction}

Adolescence begins at puberty and extends to late teens and early twenties [1].

During this period, adolescents change physically, emotionally, intellectually, and socially [2]. Adolescent life is often confusing and changing so quickly that adolescents do not always adjust effectively [3]. The period is a highly disruptive period characterized by rebellion and periods of stress [4]. Nevertheless, adolescents go through change, characterized by the need to adjust to a variety of physical changes, peer pressure, identity crisis, lifestyles, and relationship with others.

Adolescence is divided into three periods; the early stage (11-12 years), middle (13-15 years), and late adolescence (16-21 years) [1]. This study indicates that adolescents at different stages may experience different behavioural and emotional problems.

The adolescents' behavioral and emotional problems exist on a continuum; as such it is not easy to separate troubling behavioral from emotional problems. Some of the behavioral problems portrayed by adolescents are conduct disorder, aggressiveness, fighting, lying, stealing, fighting and sleeping problems [3]. Common emotional problems on the other hand include: depression, ADHD, and PTSD [5]. Adolescents exhibit these problems even before admission to the Kirigiti and Dagoretti rehabilitation centers. It is also likely that some girls develop these problems while they are in these centers.

Behavioral and emotional problems have been identified as major problems among adolescents incarcerated in rehabilitation schools [6]. The rise in emotional and behavioral problems among adolescents in rehabilitation schools in Kenya and the resultant adverse effects have led to a simultaneous increase in number of adolescents in need of professional help [3]. However, few corresponding evidence-based treatment modalities targeting adolescents in rehabilitation schools in Kenya were identified by the researcher. There are a number of corrective interventions to deal with behavioral and emotional problems among girls incarcerated in rehabilitation centers [7] which have varying levels of effectiveness. Some of the interventions mainly used are Strategic family Therapy, play and art therapy, person-centred therapy as well as gestalt therapy [8], none of which seems to address many of the systems within the girls' ecological milieu, such as family and schools and peers that contribute to and precipitate adolescents' behavioral and emotional problems.

As of 2011 there were 1.2 billion young people in the world aged $10-19$ years which translates to about $18 \%$ of the world's population [9]. In another study [10] reported that globally young people committed $40 \%$ of robberies, felony and assaults. In addition, he noted that approximately $50 \%$ of the youth engaged in hard drugs abuse and peddling. [11] noted that adolescents aged 13-19 years were responsible for approximately $25 \%$ of major offences, with many of the criminal offences being 
caused by the youth with emotional and behavioral problems.

The problem of juvenile delinquency is a challenge for many countries [12]. In the US, for example, approximately 3.2 million youths under the age of 18 years were arrested in 2009 [7] while in 2010, more than 70,000 children were held in juvenile jails [3]. In India 42,508 juveniles were apprehended and taken to court in 2012 [13]. A study done by [7] noted that some of the adolescents in rehabilitation institutions ended up becoming criminals in adulthood. It is therefore necessary to give the appropriate intervention to prevent adolescents from graduating into criminal tendencies in adulthood.

The challenge of juvenile crime in developed countries is not drastically different from developing countries. Juvenile crimes present fundamental challenge in Africa. In South Africa, children aged between 12 and 22 years constituted a considerable percentage of both victims and perpetrators [14]. However, since 2003 the number of children imprisoned in South Africa across all categories, have declined rapidly from 4500 to 846 in February 2010 [15]. In the year 2012, about 3600 adolescents were incarcerated in rehabilitation centres in Nigeria [16].

The challenge of juvenile crime in Kenya appears similar to the experience in other parts of the world. The number of juvenile delinquents that joined rehabilitation schools had been increasing from the year 1990; with total juvenile arrest rates peaking in 1996 at 9,443 per 100,000 youth aged 10 to 18 and fell by one-third in 2008 to 6,318 [17]. This trend has however changed with the current juveniles in custody having increased by over $60 \%$ (2008 - 2012) from 6,318 to 13,108 to 13,108 [17]. The number of new juveniles coming into the rehabilitation institutions as at 2012 was 1800 adolescents [18], most of them having been found in street families as well as in regular homes. Very few attend schools with most of them being apprehended for committing crimes such as; disorderly conduct, drug and substance offences, prostitutions, truancy, loitering, as well as handling of stolen property. Others join rehabilitation schools for care and protection. They stay in these schools for a maximum of three years only, after which they are released to join their families.

At the same time, some youths released from incarceration are rearrested and readmitted to rehabilitation schools for similar or different offences [19]. On distribution of juvenile crime across the counties of Kenya, Nairobi region had the highest incidences compared to the other areas in Kenya [19].

Research indicates that the majority of the incarcerated adolescents in the rehabilitation schools were from poor socio-economic background. A study carried out in Nairobi juvenile court indicated that over $70 \%$ of the children appearing in Nairobi Juvenile Court were from the slums and the street [20]. Another study done by[6] noted that the prevalence of crime among Kenyan children is high, with $80 \%$ of the crimes being poverty-related such as theft, prostitution, drug peddling, and truancy. Their study revealed that $78 \%$ of those who appeared in juvenile courts were male while $22 \%$ were females.

Adolescents incarcerated in Dagoretti and Kirigiti rehabilitation centers have behavioral and emotional problems. A study conducted by [21] in Nairobi indicated that $60 \%$ of the children and young person appearing in juvenile courts had emotional and behavioral problems. [6] argued that putting adolescents in rehabilitation centers may not be enough to rehabilitate them. To promote psychological health and deal with behavioral and emotional problems among adolescents in rehabilitation centres, treatment programmes should focus on systems that contribute to the adolescents psychopathology report [22]. Hence a reduction of the behavioural and the emotional problem among the youth in the rehabilitation schools would be expected to positively impact most on their psychological well-being [6].

\section{Procedure and Methods}

The participants in this study included 78 purposefully sampled adolescents incarcerated at Kirigiti and Dagoretti rehabilitation schools. They were recruited for the study after [23] YSR 11-18 was administered to them. They were diagnosed with DSM-V psychiatric disorders, including depressive disorder, anxiety disorder and conduct disorder. The age range of the adolescents recruited was 11-17 years with a mean age of 14.89 years, median of 15 years and standard deviation of 2.04 years. The adolescents were categorized into three groups: 11 to 12 years, 13-15 years and 16 to 17 years. They were also screened for the PTSD and ADHD

As all the adolescent girls in this study were below 18 years of age, consent for interviewing them was requested from the school management. In addition, the assent from the adolescents was obtained prior to the research. The relevant protocol through the Director of Children's Department was followed to enable the researcher conduct the study. Seven participants withdrew from the study due to absenteeism, home visit, as well as sickness occasioning an attrition rate of $8.2 \%$.

Prior to the testing, all the participants were oriented to the administration protocol and the nature of the procedure. In addition verbal and written explanations of the study were provided. They were also informed early that the study participation was voluntary, and that they could withdraw their informed consent at any time during and after testing. If subjects had difficulties understanding the procedure, additional explanations were provided. Legal information such as the legal status of the participants, reasons for convictions and length of stay were collected from the admission file information. The protocol however, excluded those who were below 11 years. Since YSR is designed for persons aged 11 to 18 years.

Socio-economic backgrounds of the adolescent girls in the study were assessed using socio-demographic questionnaire. This is a self-administered questionnaire about subjects' background as well as the reasons for incarceration. It was filled by the participants in the presence of the researcher. The filling of sociodemographic questionnaire lasted for about 25 minutes while YSR took 40 minutes.

Juvenile behavioral and emotional problems were assessed with youth self- report (YSR). The YSR contains a list of 118 specific problems in children and adolescents. It has been standardized on a sample between 11 to 18 years, and consists of two broad scales that reflect externalizing and internalizing domains. The internalizing 
composite consists of the anxious, depressed, somatic complaints and social withdrawal subscale while the externalizing composite consists of the aggressive and delinquent behavior subscale. Internal consistency $(>0.90)$ test retest reliability, $(0.86-0.90)$ and factorial validity were found to be good (2) [23].

The researcher used YSR to assess depressive disorder, anxiety disorder and conduct disorder, as well as attention deficit hyperactivity disorder and post-traumatic stress disorder. Where a respondent had any challenge, the researcher employed clinician administered format and referred to the YSR manual for detailed scoring information.

Data analysis using SPSS version 21 to describe each category of DSM-V diagnosis of participants was done by summing up the responses to meet the DSM-V criteria for depression, anxiety, conduct disorder, attention deficit hyperactivity disorder and post-traumatic stress disorder. Probability values of equal or less than $0.05(\leq 0.05)$ was taken to be statistically significant.

Table 1. Characteristics of the Study Population

\begin{tabular}{ccc}
\hline Years & Frequency & Percent \\
\hline 11 yrs & 2 & 2.6 \\
$12 \mathrm{yrs}$ & 1 & 1.3 \\
$13 y r s$ & 6 & 7.7 \\
$14 \mathrm{yrs}$ & 18 & 23.0 \\
$15 \mathrm{yrs}$ & 24 & 30.8 \\
$16 \mathrm{yrs}$ & 21 & 26.9 \\
$17 \mathrm{yrs}$ & 6 & 7.7 \\
Total (n) & 78 & 100.0 \\
\hline
\end{tabular}

\section{Results}

All the 85 participants enrolled for this study. They participated in the study from the beginning to the end except for the seven who left due to absenteeism, home visit and sickness.

There was an attrition rate of $8.2 \%$. Eventually the study had 78 respondents out of 85 . To this end therefore a total of 78 participants were enrolled in two schools. Kirigiti had (38) and Dagoretti (40). Kirigit was the experimental center while Dagoretti was the control center.

Table 2. Study Population Class Placement

\begin{tabular}{ccc}
\hline Class & Frequency & Percent \\
\hline Four & 17 & 21.8 \\
Five & 14 & 17.9 \\
Six & 13 & 16.7 \\
Seven & 31 & 39.8 \\
Above 8 & 3 & 3.5 \\
Total (n) & 78 & $100 \%$ \\
\hline
\end{tabular}

In regard to schooling, all the 78 girls were in school, as presented in Table 2. This Table represents distribution of the participants according to current class placement at the rehabilitation centers, meaning that the girls were engaged in school activities at the centers. Only 3 girls were not in primary school, but were involved in vocational skills training in hair dressing. At the time of the study, the three girls were training as hair dressers since the institution did not have a high school curriculum. The study did not include standard 8 because they were about to start their KCPE at the time of the study. The age range of participants was six years. The youngest were aged 11 years while oldest were 17 years with a median age of 15.0 and variance of 4.17 , as shown in Table 1 .

According to Table 3, class six had the lowest number of girls at 13. Maximum age in this study was 17 years, while the minimum age was 11 years. The average age was 14 and standard deviation was 0.66. The simple majority girls were in class seven.

Table 3. Descriptive Statistics Showing the Age for Various Class Categories

\begin{tabular}{ccccccc}
\hline & Class & & $\mathrm{N}$ & Minimum & Maximum & Mean \\
\hline 4 & Age & 17 & 11.00 & 16.00 & 13.6471 & 1.41161 \\
5 & Age & 14 & 13.00 & 16.00 & 1.02711 & 14.8571 \\
6 & Age & 13 & 14.00 & 16.00 & 14.5385 & 15.6129 \\
7 & Age & 31 & 14.00 & 17.00 & .66023 & .91933 \\
Form & Age & 3 & 16.00 & 17.00 & .57735 \\
\hline
\end{tabular}

Table 4. Comparison between Kirigiti and Dagoretti Schools in Terms of Social Demographic Variables

\begin{tabular}{|c|c|c|c|}
\hline Background & Experimental & Control & P Value \\
\hline Age & 14.3674 (95\% CI: 14.3674 - 15.2542) & 14.8684 (95\% CI: 14.4628 - 15.2740) & 0.001 \\
\hline Class (mean) & 5.73 (95\% CI: $5.31-6.15)$ & 5.82 (95\% CI: $5.43-6.20)$ & 0.002 \\
\hline Class (median) & 6.00 & 6.00 & 0.021 \\
\hline \multicolumn{4}{|l|}{ Religion } \\
\hline Catholic & 16/38 (42.1\%; 95\% CI: $26.4 \%$ to $57.8 \%)$ & 19/40 (47.5\%; 95\% CI:32.02\% to $62.98 \%)$ & 0.0374 \\
\hline Protestants & 16/38 (42.1\%; $95 \%$ CI: $26.4 \%$ to $57.8 \%)$ & 20/40 (50.0\%; 95\% CI:34.51\% to $65.49 \%)$ & \\
\hline Islam & 6/38 (15.8\%; $95 \%$ CI: $4.2 \%$ to $27.4 \%)$ & 1/40 (2.5\%; 95\% CI: $-2.34 \%$ to $7.34 \%)$ & \\
\hline \multicolumn{4}{|l|}{ School dropouts } \\
\hline Yes & 24/38 (63.2\%; 95\% CI: $47.87 \%$ to $78.53 \%)$ & $22 / 40$ (55.0\%; 95\% CI: $39.58 \%$ to $70.42 \%)$ & 0.0464 \\
\hline No & 14/38 (36.8\%; 95\% CI: $21.47 \%$ to $52.13 \%)$ & $18 / 40$ (45.0\%; $95 \%$ CI: $29.58 \%$ to $60.42 \%)$ & \\
\hline \multicolumn{4}{|c|}{$\begin{array}{l}\text { Disadvantaged Family } \\
\text { Social Economic Status }\end{array}$} \\
\hline Yes & 30/38 (78.9\%; 95\% CI: $65.93 \%$ to $91.87 \%)$ & 34/40 (85.0\%; 95\% CI: $73.93 \%$ to $96.07 \%)$ & 0.486 \\
\hline No & 8/38 (21.1\%; 95\% CI: 8.13\% to 34.07\%) & 6/40 (15.0\%; 95\% CI: 3.93\% to $26.07 \%)$ & \\
\hline \multicolumn{4}{|l|}{ Single Families } \\
\hline No & 14/38 (36.8\%; 95\% CI: $21.47 \%$ to $52.13 \%)$ & $12 / 40$ (30.0\%; $95 \%$ CI: $15.8 \%$ to $44.2 \%)$ & \\
\hline
\end{tabular}


Table 5. Comparison between Kirigiti and Dagoretti Rehabilitation Schools in Terms of Behavioral Problems

\begin{tabular}{|c|c|c|c|}
\hline Background & Experimental & Control & P-value \\
\hline Anxiety disorders & 5.8378 (95\% CI: $4.9969-6.6788)$ & 3.7895 (95\% CI: 2.9277 - 4.6512) & 0.011 \\
\hline Conduct disorders & 7.3784 (95\% CI: 5.6996 -9.0572) & 7.2632 (95\% CI: 6.0341 - 8.4923) & 0.003 \\
\hline $\begin{array}{l}\text { Affective Problems - Depression } \\
\text { Attention deficit Hyperactivity } \\
\text { Disorder (ADHD) }\end{array}$ & 10.2973 (95\% CI: 9.0650 - 11.5295) & 7.1579 (95\% CI: $6.1658-8.1500)$ & 0.004 \\
\hline Yes & 21/38 (55.3\%; 95\% CI: $39.49 \%$ to $71.11 \%)$ & $28 / 40$ (70.0\%; $95 \%$ CI: $55.8 \%$ to $84.2 \%)$ & 0.178 \\
\hline No & $17 / 38$ (44.7\%; $95 \%$ CI: $28.89 \%$ to $60.51 \%)$ & $12 / 40$ (30.0\%; $95 \%$ CI: $15.8 \%$ to $44.2 \%)$ & \\
\hline \multicolumn{4}{|l|}{$\begin{array}{l}\text { Post-traumatic Stress } \\
\text { Disorder(PTSD) }\end{array}$} \\
\hline Yes & 34/38 (89.5\%; 95\% CI: $79.75 \%$ to $99.25 \%)$ & $31 / 40$ (77.5\%; 95\% CI: $64.56 \%$ to $90.44 \%)$ & 0.0156 \\
\hline No & 4/38 (10.5\%; 95\% CI: $0.75 \%$ to $20.25 \%)$ & 9/40 (22.5\%; 95\% CI: $9.56 \%$ to $35.44 \%)$ & \\
\hline
\end{tabular}

Table 6. The Prevalence of Behavioral and Emotional Problems of Adolescent in Kirigiti and Dagoretti Group

\begin{tabular}{|c|c|c|c|c|}
\hline & & \multicolumn{2}{|c|}{ Emotional problems } & \multirow{2}{*}{$\begin{array}{l}\text { Behavioral problems } \\
\text { Prevalence of Conduct Disorders (n, \%); } \\
95 \% \text { CI }\end{array}$} \\
\hline & & $\begin{array}{l}\text { Prevalence of Affective Problems- } \\
\text { Depression (n, \%); 95\% CI }\end{array}$ & $\begin{array}{l}\text { Prevalence of Anxiety Disorders (n, \%); } \\
95 \% \text { CI }\end{array}$ & \\
\hline Overall pre & nce & $\begin{array}{l}52 \text { / } 78 \text { (66.7\%;95\% CI: } 56.24 \% \text { to } \\
77.16 \%)\end{array}$ & $\begin{array}{l}55 \text { / } 78 \text { (70.5\%;95\% CI } 60.38 \% \text { to } \\
80.62 \%)\end{array}$ & $\begin{array}{l}43 \text { / } 78 \text { (55.1\%; } 95 \% \text { CI: } 44.06 \% \text { to } \\
66.14 \%)\end{array}$ \\
\hline \multirow{2}{*}{ Study sites } & Kirigiti & $\begin{array}{l}30 / 38 \text { (78.9\%; } 95 \% \text { CI } 65.93 \% \text { to } \\
91.87 \%)\end{array}$ & $\begin{array}{l}33 / 38 \text { (86.8\%; } 76.04 \% \text { to } 97.56 \% \% \text {; } \\
95 \% \text { CI) }\end{array}$ & $\begin{array}{l}\text { 20/38 (52.6\%; 95\% CI: } 36.72 \% \text { to } \\
68.48 \%)\end{array}$ \\
\hline & Dagoretti & $\begin{array}{l}22 / 40 \text { (55.0\%;95\% CI:39.58\% to } \\
70.42 \%)\end{array}$ & $\begin{array}{l}22 / 40 \text { (55.0\%;95\% CI: } 39.58 \% \text { to } \\
70.42 \%)\end{array}$ & $\begin{array}{l}23 / 40 \text { (57.5\%; 95\% CI: } 42.18 \% \text { to } \\
72.82 \%)\end{array}$ \\
\hline
\end{tabular}

Table 4 presents a comparison between Kirigiti and Dagoretti schools at baseline. According to the table, the age of the respondents in Dagoretti and Kirigiti groups were comparable; 14.3 years and 14.8 years respectively. Class means in both groups were almost the same; 5.73 in Kirigiti and 5.82 in Dagoretti. Standard six was the median class in both groups. Girls who came from disadvantaged socio-economic status were $78.9 \%$ in Kirigiti and 85\% in Dagoretti. The majority of the girls came from Single families, $63.2 \%$ in Kirigiti and $70 \%$ in Dagoretti. Half of the girls had dropped out of school prior to incarceration; 63.2\% and 55\% in Kirigiti and Dagoretti respectively. Participants who had ADHD at Kirigiti and Dagoretti were $55.3 \%$ and $70 \%$ respectively. In addition those who had PTSD were $89.5 \%$ in Kirigiti and $77.5 \%$ in Dagoretti. ADHD and PTSD were equally distributed in the two groups. These results indicate that ADHD and PTSD were confounders in the study.

Table 6 presents the prevalence of behavioural and emotional problems of adolescent girls incarcerated at Dagoretti and Kirigiti rehabilitation schools. According to the table, girls who exhibited depression in the experimental and control groups were $78.9 \%$ and 55\% respectively. Anxiety prevalence rate were $86.8 \%$ in the experimental and $55.0 \%$ in the control groups. In addition, the prevalence rate for conduct disorder in the experimental and control groups were 52.6\% and 57.5\% respectively. Overall prevalence of depression, anxiety and conduct disorder in both groups were $66.7 \%, 70.5 \%$ and $55 \%$ respectively. Table 5 further depicts the prevalence of depression and anxiety disorder, which appeared to be more prevalent in the Kirigiti group as compared to the Dagoretti group.

\section{Discussion}

The main finding indicates that adolescents incarcerated in rehabilitation schools were more likely to have psychiatric comorbidity. The prevalence of affective problem depression (APD), anxiety disorder (AD) and conduct disorder (CD) were 66.7\%, 70.5\% and 55\% respectively. The study indicates that most girls incarcerated in the rehabilitation schools were depressed. The finding supports previous studies that confirmed the existence of depressive disorder among incarcerated adolescents. In agreement, [2] noted that rehabilitation centers are extremely stressful for incarcerated adolescents partly because they have little control of their environment. In addition research indicates that high level of depression and anxieties were common among inmates [24,25,26]. Entry shock is particularly evident in the initial stages of incarceration where adolescents with conflict with the law face disproportionate amount of stress [25].

The presence of high level of depression and anxiety among incarcerated girls indicates that females are more prone to depressive circumstances. This finding supports a study done by [27] who noted high likelihood for high depressive disorder among incarcerated girls in rehabilitation schools as compared to boys in the same institutions. High rates of anxiety disorder have been found repeatedly among incarcerated girls [26]. This study was therefore not an exception as $70.5 \%$ of the sampled girls in Kirigiti and Dagoretti met the diagnostic criteria for anxiety disorder. Prevalence rate of anxiety disorder among them was substantially higher than for adolescent male in the community [27].

The prevalence of conduct disorder in this study was $55.1 \%$. This research agrees with [28] that conducts disorder is highly prevalent among juvenile incarcerated in rehabilitation schools. This study revealed that adolescents involved in juvenile delinquency have psychological comorbidity. This study further agrees with [29] that conduct disorder often occurs with attention deficit hyperactivity disorder as well as post-traumatic stress disorder. Effectiveness of Multisystemic therapy was lowest on conduct disorder as compared to depression and anxiety disorder, due to unavailability of family 
intervention. [30] noted that family intervention is an essential component of treating conduct disorder.

There is also evidence that MST is an effective intervention for conduct disorder delivered in family and community setting [31]. The study revealed that most of the adolescents with conduct disorder originated from single parent families. [32] noted that family background can have an influence on many domains of development problems especially conduct disorder. The majority of adolescents in the study had high psychiatric morbidity. This is in agreement with a study by [21] who noted that psychiatric morbidity among incarcerated adolescents was $80 \%$.

The prevalence of ADHD among the study population was $62.8 \%$. This occurrence is supported by [13] that between, $21 \%$ to $45 \%$ of children incarcerated in rehabilitation centers have ADHD. [13] also revealed that children with ADHD are four to nine times more likely to have conflict with the law. The study revealed that those with ADHD accumulated comorbid conditions, such as depression, and PTSD. This study is in agreement with [29] who noted that young people with ADHD have high rates of depression, anxiety and conduct disorder. If left untreated ADHD will lead to other psychological problems [33].

The study indicates that $83.3 \%$ of the adolescents had PTSD and those with PTSD had significantly more behavioural and emotional problems. Studies on incarcerated adolescents in Kenya found that most of the incarcerated children had at least one additional or comorbid psychological disorder such as depression, anxiety and conduct disorder [27].

The study found out that exposure to trauma was common among incarcerated adolescents. The findings are comparable to report from studies of children in rehabilitation centers by [6]. The conditions of confinement often exacerbate symptoms of mental disorders [34]. It is thus important for the Juvenile Justice System, law enforcement and mental health systems to incorporate knowledge of mental illness in the programme. [35] found that two-thirds of adolescents with depression had at least one comorbid psychiatric disorder. They noted that adolescents with depression were six to twelve times more likely to have anxiety, and four to eleven times more likely to have disruptive behaviour disorder. According to [34] cormorbidity is especially increased in adolescents with severe depression.

From the foregoing, the study recommends that mental health problems such as depression, anxiety, conduct disorder, ADHD and PTSD should be an integral component of the rehabilitation programmes for girls. Depression and anxiety are more frequently diagnosed in girls than in boys [36], and behavioural and emotional problems may accompany delinquency. Furthermore, Conduct disorder among girls may indicate early victimization and signify that these girls need intervention to deal with this experience. An increase in school and family centered programme may also be useful.

\section{Conclusion}

This study showed a high prevalence of psychiatric morbidity among incarcerated girls. The girls definitely need psychological support. The study adds to the existing body of research on the psychiatric morbidity of incarcerated adolescents. The main findings indicate that there was a correlation between juvenile delinquency and psychiatric cormobidity.

\section{Acknowledgements}

I thank the girls incarcerated in Kirigiti and Dagoretti rehabilitation schools for participating in this study. In addition, I am grateful to all the staff of the two schools and the Children's Department for providing logistics support.

\section{References}

[1] Barley, L. (2007). Defiant child. London: Guildford Press.

[2] Lafortune, D. (2010). Prevalence of screening of pyschiatric disorders in mental facilities. International Journal of Law and Psychiatry. 156, 837-841.

[3] Wildeman, J. (2010). The paternal incarceration and the children's physically agressive behaviours: Evidence from the fragile families and child wellbeing study. A Social Forces Study Journal, 89(2), 285-310.

[4] Enzmann, D., \& Podan, Z (2011). Official crime statistics and survey data: Comparing trends of youth violence betwen 2000 and 2006 in cities of Czech Republic, Germany, Poland,Russia and Slovenia. European Journal of Criminal Research, 16(2), 191-205.

[5] Griller, C., \& Unruh, B. (2010). Transition practice for dedicated youth emotional and behavioural disorders and related trends of disabilities. Behavioural Disorders Journal, 36(1), 43-51.

[6] Omboto, J., Ondiek, O., Odera, O., \& Ayugi, M. (2013). Factors influencing youth crime and juvenile delinquency. International Journal of Research and Socia Studies, 4(2), 18-21

[7] Mulatie, B. (2014). Parental practices of disciplining children: Implication for the major intervention. International Journal of Psychology and Counseling, 6(3), 214-249.

[8] Steinberg, T. (2013). Adolescence (10th ed.). New York: MC Graw Hill.

[9] United Nation Children Fund. (2011). The state of world children adolescent and age of oportunity. New York: UNICEF.

[10] Siegel, L. (2010). Criminology: Theory, patterns, and typologies. Australia: Wadsworth

[11] Vitulano, M., Fite, P., \& Rathert, J., (2010). Major delinquent peer influence on childhood delinquent: Moderating effect of impulsivity. Journal of Psychopathology and Behavioural Assessment, 32(1), 315-322.

[12] Granado, X., Roca, J., \& Gemma, F. (2014). Juvenile delinquency in incarcerated youths from residential care. European Journal of Social Work, 10(1), 1080-1090.

[13] Ojo, M. (2012). The sociological review of issues on juvenile delinquency. Journal of International Social Research, 5(21), 465-482.

[14] Bella, T., Atiola, O., \& Omlogbodum, S. (2010). Children within juvenile system in Nigeria: Psychopathology and psychosocial needs. Annals of Postgraduate Medicine Journal, 8(1), 220-230.

[15] Miemsie, S., Badenhorst, J., \& Kamper, G. (2010). Our role counts: Adolescents' view on their future in South Africa. South Africa Journal of Education.30(1), 169-188.

[16] UNO. (2012). World report on young people. New York: Author.

[17] Griffin, J. (2010). Juvenile in custody in Kenya. Nairobi: Calif Publishers.

[18] Watindi, J. (2012). The very late childhod and adolescent externalizing and internalizing psychopathology in rural public secondary schols in western Kenya. Journal of Emerging Trends in Educational Reserch and Policy Studies, 3(6), 113-118.

[19] Kikuvi, R. N. (2012). Determination of delinquency among the children in rehabilitation school in Kenya. Nairobi: Calif.

[20] Skelton, A. (2010). Juvenine justice in Kenya courts. Journal of International Child and Youth Care, 90(I), 310-350.

[21] Maru, H., Kathuku, D., \& Ndetei, D. (2003). Psychiatric morbidity among children and young person's appearing in the Nairobi juvenile court. East Africa Medical Journal, 2, 282-288. 
[22] Glisson, C., Schoenwald, S, Hemmelgarn, A., Green, P, Dukes, D, Armstrong, K., \& Chapman, J. (2010). Randomized trial of MST in a two-level EBT implementation strategy. Journal of Clinical Psychology, 78(2), 537-550.

[23] Achenbach, T. (2001). An interest system of the multi-informant assessment. Burlington: University of Vermont Research Centre for Children, Youth \& Families.

[24] Ahmed, A., \& Mazlan, N. H. (2014). Stress and depression: A comparison between men and women inmates in Peninsular and Malaysia. International Journal of Humanities and Social Sciences, 14(2), 153-160.

[25] Olivia, L. (2013). Treatment of female offenders in Kenya, $153^{\text {rd }}$ International Senior Seminar Participants, Papers 145-149.

[26] Tomar, S. (2013). The psychological effects of the incarceration in conflict with the law. Delhi Psychiatric Journal, 16(2), 64-72.

[27] Onyango. O. J. (2013). The challenges facing rehabilitation of the prisoners kenya and mitigation strategies. International Journal of Research in Social Sciences,2(2), 39-43.

[28] Surup, R., \& Heather, G. (2014). Community engagement for reentry success of youth from juvenile justice: Challenges and opportunuties. Education and Treatment of Children Journal, 4(1), 713-734.

[29] Ebesutani, C., Bernstein, A., Martinez, J., \& Chorpita, B. (2011) The youth self- report: Applicability and validity across younger and older youths. Journal of Clinical Child \& Adolescent Psychology, 40(2), 333-346.
[30] Mugo, J, Musembi, D., \& Kangethe, R. (2006). Juvenile justice and management of child offenders in Kenya: An annotated bibliography of research 1958-2005. Nairobi: Kenyatta University.

[31] Ngo, V. (2014). Test of facilitation VS "proximal process" moderator model for effects of MST on adolescent with severe conduct problem. Journal of Abnormal Child psychology, 9(2), 201-220.

[32] Roosa, M., Burrell, G., Nair, R., Core, S., Tein, J., \& Knight, G. (2010).Socio-economic disadvantaged students among Mexican American early adolescent. Journal of Early Adolescence, 30(1), 567-592.

[33] Butler, S., Baruch, G., Hickley, N., \& Fonagy, P. (2011). A randomized control trial of MST anda statutory therapeutic intervention for young offenders. Journal of the American Academy of Child \& Adolescent Psychiatry, 50(1), 1220-1235.

[34] Petot, D. (2011). An agreement between parent and self- reports of Algerians adolescents behavioural and emotional problems Journal of Adolescence, 2(34), 977-986.

[35] Costello, J, Foley, D, \& Angold, A. (2010). The epidemiology of child and adolescent psychiatric disorders: Developmental epidemiology. Journal of Child Adolescent Psychiatry, 45(1) 8-25.

[36] Dawson, J., \& Straus, M. (2011). Gender equality in the society and male predominance in crime by university students in two national settings. Open Criminology Journal, 4(1), 10-23. 